\title{
MEKANISME RANTAI PASOK CABE RAWIT DI PROPINSI GORONTALO
}

\author{
Mechanism Of Chili's Value Chain At Gorontalo Province \\ Indriani, R, R.Darma, Y.Musa, AN. Tenriawaru, \\ Made Viantika \\ Program Studi Agribisnis, Departemen Sosial Ekonomi Pertanian, \\ Fakultas Pertanian, Universitas Negeri Gorontalo, Gorontalo \\ ${ }^{*}$ Kontak penulis: ria.indriani@ung.ac.id
}

\begin{abstract}
Penelitian bertujuan mendeskripsikan mekanisme rantai pasok cabe rawit berdasarkan aliran produk, aliran informasi dan aliran uang, Penelitian dilaksanakan di Provinsi Gorontalo dengan metode penelitian menggunakan metode survei dan analisis deskriptif. Hasil penelitian menunjukkan : Mekanisme rantai pasok cabe rawit di Provinsi Gorontalo bersifat modern dimana aliran produk berdasarkan ketersediaan berupa cabe rawit segar dan produk olahnya. Aliran Informasi cukup lancar dan aliran uang menggunakan sistem transaksi pembayaran tunai dan kredit. Rantai pasok cabe rawit terdiri tujuh saluran distribusi dan saluran tiga merupakan saluran yang paling dominan.
\end{abstract}

Keywords : Mekanisme, supply chain

The aim of this research is to describe the supply chain mechnanism of chilis based on product, information and cash flows. This research conducted at Gorontalo Province by using surveyed and descriptive analysis methods. The result of the research shows that : the supply chain of chilis at Gorontalo Province were modern which the products flow were based on its raw chilis availabilities and its derived products. The information flow was smooth and the cash flows is using a cash payment transaction system and credts. There are seven channel distribution happened and the third channel were the dominants among all.

Keywords: Mechanism, supply chain

Indriani, R, R.Darma, Y.Musa, AN. Tenriawaru, 2019. Made Viantika , 2019. Mekanisme Rantai Pasok Cabe Rawit Di Propinsi Gorontalo, JSEP 15(1): 31 - 41.

\section{Pendahuluan}

Kebutuhan cabe rawit per kapita di Indonesia sangat fluktuatif dari tahun ke tahun. Jumlah konsumsi cabe rawit terus mengalami peningkatan seiring dengan pertambahan jumlah penduduk setiap tahun (Syukur, Yunianti, dan Dermawan, 2017). Konsumsi cabe rawit di Indonesia pada tahun 2015 sebesar 1,32 kg/kapita/tahun (Pusdatin, 2015) atau rata-rata konsumsi cabe per kapita adalah 500 gram/tahun. Hal ini berarti, dengan jumlah penduduk sebanyak 237.6 juta (BPS, 2010), Indonesia membutuhkan cabe sebesar 118.800 ton per tahun (Wahyudi, 2011).

Di pulau Sulawesi, produksi cabe rawit tertinggi berada di Sulawesi Selatan (27.543 ton), disusul Sulawesi Utara (12.783 ton), Sulawesi Tengah (11.635 ton), Sulawesi Barat (11.549 ton) dan Gorontalo (11.492 ton) (BPS dan Dirjen 
Hortikultura, 2017). Namun, menurut Astuti (2016), sentra utama produksi cabe rawit di Indonesia terdapat di enam (6) wilayah, dimana untuk wilayah Sulawesi termasuk Kabupaten Gowa, Enrekang dan Provinsi Gorontalo.

Potensi pengembangan agribisnis cabe rawit terbuka luas diluar Jawa terutama di Provinsi Gorontalo. Provinsi Gorontalo termasuk salah satu daerah sentra penghasil cabe rawit di luar pulau Jawa atau di Indonesia Timur. Kebijakan pemerintah Provinsi Gorontalo mendukung komoditas cabe rawit adalah Program Pengembangan Kawasan Cabai Rawit dengan Gertam (Gerakan tanam) Cabai Rawit se- Provinsi (Dinas Pertanian Provinsi Gorontalo, 2017). Usahatani cabe rawit di Provinsi Gorontalo memiliki prospek yang cukup besar.Komoditas cabe mempunyai daya saing yang lebih tinggi dibanding jagung dan padi. Hal ini terlihat dari nilai $\mathrm{R} / \mathrm{C}$ dan $\mathrm{B} / \mathrm{C}$ cabe $(2,15 ; 1,87)$ lebih tinggi dibandingdibanding jagung $(2,11 ; 1,83)$ dan padi $(2,03 ; 1,77)$ (Nurdin, dan kawan-kawan, 2011). Cabe rawit merupakan komoditas basis di Kabupaten Boalemo Provinsi Gorontalo dengan nilai LQ 1,15-1,83 yang berarti produksi cabe di daerah tersebut surplus 1,15-1,83 kali lebih besar dibanding kebutuhan sendiri (Nurdin, dkk. 2011). Oleh karena itu pemasaran cabe rawit selain di pasar lokal di Provinsi Gorontalo, juga di kirim ke luar daerah (Antu, dkk. 2017).

Sebenarnya komoditas cabe rawit cukup memiliki prospek akan tetapi banyak terjadi permasalahan dalam komoditas cabe rawit di Provinsi Gorontalo, salah satunya faktor cuaca dan harga yang berfluktuasi (Farid dan Subekti, 2012 ; Potolau, et.al. 2013). Seperti komoditas pertanian lainnya, cabe rawit secara umum mempunyai karakteristik yang khas antara lain: (1) produk mudah rusak, (2) budidaya dan pemanenan sangat tergantung iklim dan musim,(3) kualitas bervariasi dan (4) bersifat kamba atau bulky (5) Lebih mudah terserang hama dan penyakit dan (6)Berfungsi sebagai produk sosial (Yandra et. al., 2007 ; Rahim dan Hastuti, 2007).

Pasokan cabe tidak mudah diprediksi, karena sifat produksinya yang khas. Pada musim hujan budidaya cabe berpotensi terkena penyakit, sedang pada musim kemarau, budidaya cabe berpotensi terkena hama. Semakin pasokan cabe sulit diprediksi, maka risiko yang ditanggung pelaku semakin besar (Farid dan Subekti, 2012 ; Potolau dkk, 2013).Oleh karena itu rantai pasok merupakan salah satu pendekatan yang dapat mengatasi berbagai permasalahan cabe rawit. Rantai Pasok merupakan konsep dalam menerapkan sistem logistik yang terintegrasi (Marimin \& Magfiroh, 2013), yaitu konsep tentang mata rantai penyediaan barang dari bahan baku sampai barang jadi (Indrajit \& Djokopranoto, 2002), yang meliputi produsen, pemasok, pengangkut, gudang, pengecer, pelanggan (Chopra dan Meindl, 2004 dalam Vorst, 2006). Dalam satu waktu, proses paralel, dan berurutan dapat terjadi dalam rantai pasok pertanian sehingga proses bisnis didalam jaringanrantai pasok pertanian akan teridentifikasi lebih dari satu (Vorst, 2006).

Pendekatan rantai pasok diyakini akan mampu meningkatkan efektivitas setiap rantai distribusi, sehingga menjamin produk sesuai tuntutan konsumen (Fatahilah et al. 2010).Rantai pasokan merupakan salah satu pendekatan yang diyakini dapat digunakan untuk menyelesaikan permasalahan komoditas cabe rawit seperti : pasokan cabe yang sulit diprediksi, fluktuasi harga, ketidakpastian produksi, cuaca ekstrim, panjangnya saluran distribusi, transportasi, dan stabililisasi harga.

Kenaikan harga cabe rawit terjadi setiap minggu. Kenaikan tersebut dipacu oleh sedikitnya pasokan cabe rawit yang beredar dipasaran karena terganggu oleh beberapa hal mulai dari cuaca hingga proses distribusi. Faktor cuaca yang tidak menentu dapat berimplikasi pada ketidakpastian jumlah produksi yang akan mempengaruhi pasokan cabe rawit berakibat pada harga jual cabe rawit yang tidak pasti dan umumnya mengikuti mekanisme pasar. Selain itu, keterlambatan akibat transportasi maupun hujan yang berkepanjangan juga membuat proses pembusukan cabe rawit semakin cepat (Hartik, 2017). Upaya yang dilakukan oleh pemerintah untuk menstabilkan harga dengan meratakan pasokan didaerah-daerah yang kekurangan (Rachman, 2017), dimana daerah yang surplus seperti Gorontalo dikirimkan kedaerah yang kekurangan, seperti Kalimantan, menyebabkan 
harga cabe rawit di Gorontalo ikut naik.

Kondisi harga cabe rawit yang berfluktuasi ini diakibatkan oleh pengaturan manajemen rantai pasok yang tidak efisien. Efisiennya manajemen rantai pasok dapat tercapai jika pengelolaan dan pengawasan hubungan saluran distribusi dilakukan secara kooperatif oleh semua pihak yang terlibat. Bentuk pengaturan rantai pasok sangat perlu mendapat perhatian khusus. Adanya pendekatan rantai pasokan komoditas cabe rawit diharapkan dapat memberikan gambaran ketersediaan pasokan cabe rawit sebagai pertimbangan pengelolaan supply chain cabe rawit bagi konsumen maupun agroindustri. Atas pertimbangan tersebut, identifikasi mekanisme rantai pasok cabe rawit terkait aliran produk, aliran informasi dan aliran uang di Propinsi Gorontalo menjadi tujuan pada penelitian ini.

\section{Metode Penelitian}

Jenis penelitian yang digunakan dalam penelitian ini adalah penelitian deskriptif dengan metode penelitian survei melalui pengumpulan informasi dari responden menggunakan kusioner, dimana informasi dikumpulkan dari sebagian populasi untuk mewakili seluruh populasi (Singarimbun, 1982).

Penelitian ini dilaksanakan di Provinsi Gorontalo yang berpusat di Kabupaten Pohuwato dan Kabupaten Gorontalo Utara karena merupakan daerah dengan produksi dan produktivitas tertinggi untuk cabe rawit di Provinsi Gorontalo, sehingga memungkinkan pengumpulan data karena dianggap memiliki rantai pasok, pedagang besar dan prospek pasar yang cukup jelas. Pengambilan sampel menggunakan teknik snowball sampling. Pengumpulan data rantai pasok di mulai dari tingkat pedagang besar,agar lebih mudah mendapatkan data di tingkat di pedagang pengumpul, pedagang pengecer dan petani. Jumlah responden terdiri dari 30 orang petani cabe rawit, 10 orang pedagang pengumpul, 12 orang pedagang besar, dan 12 orang pedagang pengecer. Pengumpulan data penelitian menggunakan teknik : observasi, dan wawancarakepada semua responden dengan menggunakan kuesioner (daftar pertanyaan) yang berisi aspek-aspek yang dianalisis dan dokumentasi.

Analisis deskriptif digunakan untuk mengkaji mekanisme rantai pasok cabe rawit terkait aliran material, informasi dan uang serta implikasi kinerja rantai pasok cabe rawit di Gorontalo.

\section{Hasil dan Pembahasan}

Mekanisme rantai pasok produk pertanian dapat bersifat tradisional ataupun modern. Mekanisme tradisional adalah petani menjual produknya langsung ke pasar atau lewat tengkulak, sedangkan mekanisme rantai pasok modern melibatkan manufaktur, pasar swalayan, dan pedagang besar (Marimin dan Magfiroh, 2013). Mekanisme rantai pasok cabe rawit di Provinsi Gorontalo bersifat modern, karena melibatkan petani sebagai pemasok cabe rawit, pedagang pengumpul, pedagang besar, pengecer sebagai pelanggan. dan agroindustri sebagai processor. Rantai pasokan cabe rawit di Provinsi Gorontalo terdiri dari anggota primer dan sekunder. Anggota primer adalah pihak-pihak yang terlibat secara langsung dalam kegiatan bisnis rantai pasokan. Anggota sekunder adalah anggota rantai pasokan yang tidak langsung berhubungan dengan kegiatan produksi namun memiliki pengaruh dalam kegiatan bisnis (Subarkah, 2009).

Anggota primer rantai pasok cabe rawit terdiri dari petani, pedagang pengumpul, pedagang besar, pedagang luar kota, pedagang pasar, pedagang pengecer, konsumen dan agroindustri. Koordinasi antar anggota didasari oleh kesadaran bahwa kuatnya rantai pasokan tergantung pada kekuatan seluruh elemen yang ada di dalamnya.Aliran produk cabe rawit segar yang dihasilkan petani di Provinsi Gorontalo melibatkan pedagang 
pengumpul, pedagang besar, pedagang pasar, pedagang pengecer dan pedagang luar kota. Pada tahap produksi ditingkat petani sumber sarana produksi khusus bibit berasal dari petani itu sendiri, pedagang pengumpul, sesama petani, dan toko tani. Toko tani menjual pupuk, obat-obatan, dan alat-alat pertanian. Pada tahap produksi dilakukan mulai dari penyiapan lahan, penanaman, pemeliharaan, dan panen.

Dalam rantai pasok cabe rawit di Propinsi Gorontalo, aliran informasi dibedakan menjadi dua macam, yaitu aliran informasi yang mengalir secara horizontal dan aliran informasi yang mengalir secara vertikal. Aliran informasi secara horizontal hanya terjadi ditingkat petani cabe rawit. Aliran informasi secara horizontal dikalangan petani cabe rawit ini berupa sharing atau tukar pendapat tentang teknik budidaya, teknik olah tanah dan pemilihan benih unggul yang dapat meningkatkan hasil produksi. Sedangkan aliran informasi secara vertikal yang terjadi antar mata rantai dalam rantai pasokan komoditas cabe rawit di Provinsi Gorontalo.

Pada umumnya aliran informasi antara petani dengan lembaga pemasaran lainnya sangat lancar terutama soal ketersediaan cabe rawit, dan kebutuhan cabe rawit. Penggunaan alat komunikasi sangat menunjang aliran informasi dimana harga cabe rawit juga berfluktuasi karena tergantung dengan harga pasar di luar kota Gorontalo. Namun aliran informasi mengenai harga kurang transparan. Pedagang cabe rawit kurang terbuka mengenai harga jual cabe rawit sebenarnya kepada petani. Aliran informasi tidak berjalan dengan lancar dan seimbang, menyebabkan petani tidak mengetahui informasi yang dimiliki khususnya pedagang pengumpul dan pedagang besar, sehingga petani tidak dapat menentukan posisi tawarnya dalam pembentukan harga. Tidak lancarnya aliran informasi harga ini sesuai dengan struktur pasar yang terjadi dimana pedagang memiliki kekuatan oligopsoni yang dapat mengendalikan harga beli dari petani.. Menurut Pujawan dan Mahendrawathi (2017), informasi sangat penting untuk kinerja rantai pasok karena informasi menjadi dasar pelaksanaan proses rantai pasok. Selain itu, informasi harus memiliki beberapa karakteristik agar berguna dalam mengambil keputusan rantai pasok, yaitu: akurat, tepat dan dapat diakses saat dibutuhkan (Chopra dan Meindl, 2007).

Aliran uang merupakan penyaluran nilai dalam bentuk rupiah. Aliran keuangan tersebut terdiri dari komponen biaya serta keuntungan yang diterima oleh setiap mata rantai yang terlibat (Kurniawan, dkk. 2013). Aliran uang pada rantai pasok cabe rawit di Gorontalo terdiri dari dua bentuk yaitu sistem pembayaran secara tunai dari petani dengan lembaga pemasaran lainnya sampai dengan pedagang pengumpul, pengecer dan pedagang pasar. Dan pembayaran secara kredit antara pedagang besar dengan pedagang luar kota. Penentuan harga cabe rawit dilakukan oleh pedagang besar atau pedagang luar kota. Harga jual cabe rawit di tingkat petani bervariasi tergantung penjualannya ke jenis pedagang. Mekanisme aliran uang pada rantai pasok cabe rawit di Provinsi Gorontalo ditekankan pada bagaimana sistem transaksi pembayaran yang digunakan baik tunai maupun kredit oleh masing-masing mata rantai melalui Bank Rakyat Indonesia terutama pedagang besar dan pedagang luar kota.

Aliran uang pada rantai pasok cabe rawit menunjukkan bahwa harga pembelian di tingkat pedagang pengumpul paling murah dibanding lembaga pemasaran lainnya. Jika harga cabe rawit murah kebanyakan petani lebih suka menjual ke pedagang pengecer, sedangkan jika harga cabe rawit mahal dan volume panennya sedikit maka petani lebih suka menjual ke pedagang besar karena lebih untung. Seringkali pasokan cabe rawit dari pedagang pengumpul dibeli seluruhnya oleh pedagang besar namun harga cabe menjadi turun. Fluktuasi harga sering terjadi dimana pada pagi hari harganya mahal, sore harinya cabe rawit sudah turun. Di tingkat pedagang pengumpul, jika volume cabe rawit jumlahnya besar, pengumpul lebih suka menjual ke pasar lokal atau dikirim ke Manado, sedangkan pada saat pasokan cabe rawit sedikit jumlahnya dan harganya mahal, maka pengumpul lebih suka menjual ke pedagang pengecer. Di tingkat pedagang pengecer cabe rawit yang tidak laku kemudian dijemur menjadi cabe rawit kering (rica kering). Hasil ini sejalan dengan 
Ongirwalu, dkk (2015) bahwa Cabai atau rica menjadi salah satu komoditi vital di Sulawesi Utara karena menjadi bumbu utama untuk sebagian besar masakan sehingga harus selalu tersedia, meski sering kali harganya mahal akibat kurangnya stok di pasaran.

Proses distribusi cabe rawit membentuk saluran yang menghubungkan setiap pelaku rantai pasok cabe rawit di Provinsi Struktur rantai pasok produk pertanian tidak selalu mengikuti urutan rantai dimana petani dapat langsung menjual hasil pertaniannya langsung ke pasar, sehingga telah memutus rantai pelaku tengkulak, manufaktur dan distributor (Marimin \& Magfiroh, 2013). Struktur rantai pasok cabe rawit dan pola aliran produk, informasi dan uang dalam Rantai Pasok Cabe Rawit di Provinsi Gorontalodapat dilihat pada Gambar 1

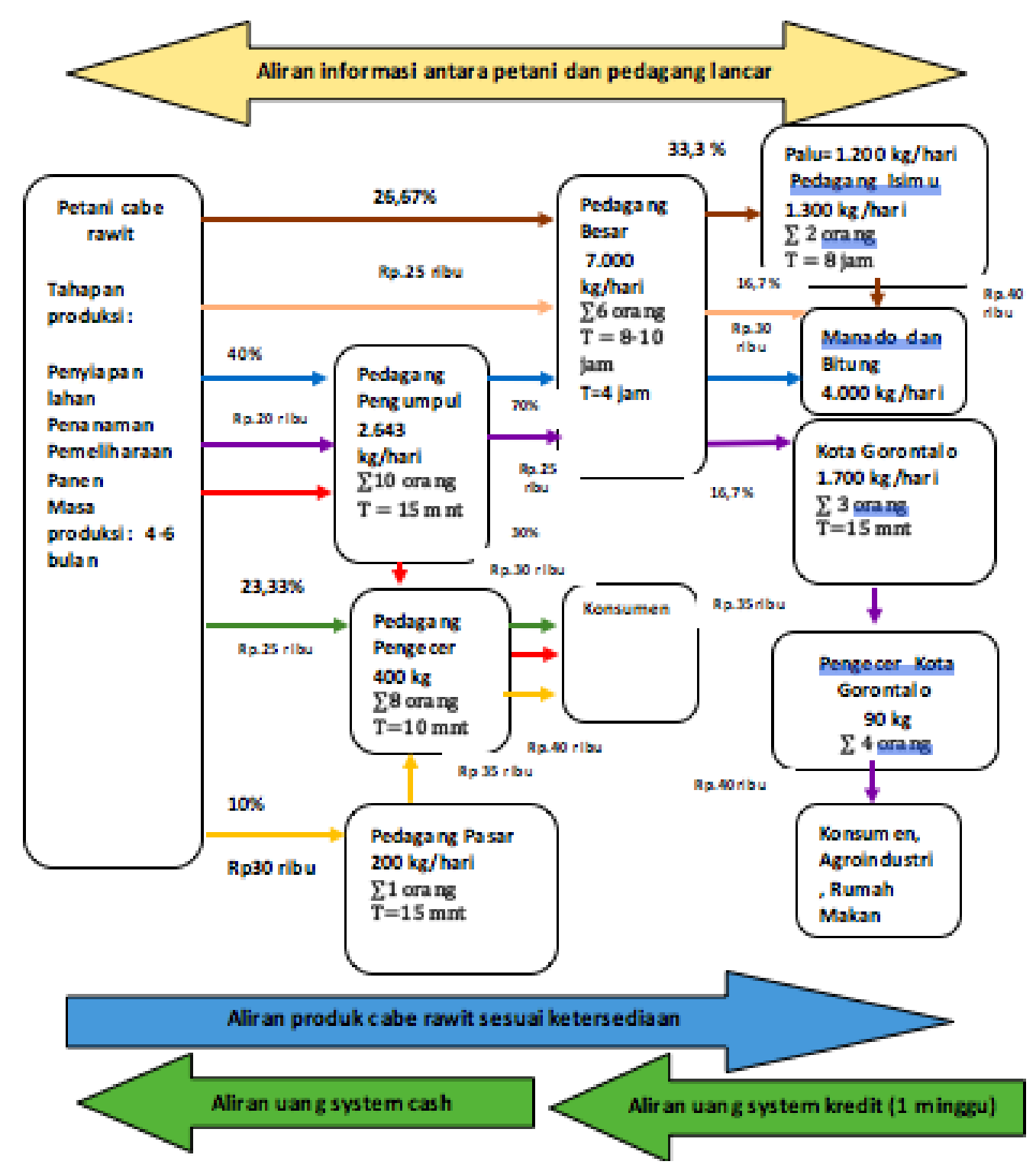

Gambar 1. Pola Aliran Produk, Informasi dan Uang dalam Rantai Pasok Cabe Rawit di Provinsi Gorontalo, 2018. 


\section{Kesimpulan}

Mekanisme rantai pasok cabe rawit di Provinsi Gorontalo bersifat modern karena melibatkan petani cabe rawit, pedagang besar, pengumpul, pengecer, agroindustri, toko tani, perbankan, penyedia jasa angkutan, Dinas Pertanian, dan media informasi. Terdapat tujuh saluran distribusi cabe rawit di Gorontalo dengan saluran yang dominan adalah saluran tiga (petani $\rightarrow$ pengumpul $\rightarrow$ pedagang besar $\rightarrow$ Manado) dimana 16,67 persen petani memilih menjual ke 70 pengumpul dan 50 persen pedagang besar. Aliran produk rantai pasok cabe rawit berdasarkan ketersediaan terdiri dari dua jenis, berupa cabe rawit segar dan olahan cabe rawit. Aliran Informasi cukup lancar namun kurang transparan. Aliran uang terdiri dari dua bentuk yaitu sistem pembayaran secara tunai ditingkat petani sampai pedagang pengumpul dan sistem kredit di tingkat pedagang besar dan pedagang luar kota.

\section{Daftar Pustaka}

Aramyan, L.H.; Ondersteijn, C.J.M.; Kooten, O. van; Oude Lansink, A.G.J.M. 2006. Performance indicators in agri-food production chains. In Quantifying the agri-food supply: pp.47-64.

Artsiomchyk\&Zhivitskaya, 2015. Designing Sustainable Supply Chain under Innovation Influence. IFAC-Papersonline48-3 (2015)1695-1699.doi.10.1016/j.ifacol.2015.06.330

Asmarantaka R.W. 2012. Pemasaran Agribisnis (Agrimarketing). Departemen Agribisnis FEMIPB. Bogor.

Anwarudin, dan kawan-kawan . 2015. Dinamika Produksi dan Volatilitas Harga Cabe : Antisipasi Strategi dan Kebijakan Pengembangan. Jurnal Pengembangan Inovasi Pertanian Vol. 8 No. 1 Maret 2015: 33-42.

Antu, M.Y. dan kawan-kawan, 2017.Laporan Akhir Pendampingan Pengembangan Kawasan Hortikultura (PKAH) Komoditas Cabai Rawit Tahun 2016. Badan Penelitian dan Pengembangan Pertanian. Kementrian Pertanian. Gorontalo.

Asir, M., 2018. Revitalisasi Peran Pemangku Kepentingan dan Strategi PengendalianRisikoRantaiPasokKomoditasKakao.Disertasi.SekolahPascasarjana.

UniversitasHasanuddin. Makassar.

Astuti, S. 2016. UpayaKhusus Pengembangan Cabe Rawit Tahun 2016. Minggu, 1Mei 2016. http//m.tabloidsinartani.com/index.php.Diaksespadatanggal 20 Mei 2017.

Asmayanti, 2012.SistemPemasaranCabaiRawitMerah (Capsicum frutescens) di DesaCigedug Kecamatan Cigedug Kabupaten Garut. Skripsi. Departemen Agribisnis. Fakultas Ekonomi dan Manajemen. Institut Pertanian Bogor. Bogor.

Baruwadi, M., R. Yusuf, S. Canon, dan F. Zakaria. 2007. Road Map Pengembangan Komoditas Pertanian di Kabupaten Boalemo. Kerja Sama Lembaga Penelitian Universitas Negeri Gorontalo dengan Dinas Pertanian dan Ketahanan Pangan Provinsi Gorontalo, Gorontalo.

Beamon BM. 1999. Measuring Supply Chain Performance. International Journal of Operations and Production Management 1999; 19(3): 275-292.

Borodin et.al, 2016. Handling Uncertainty in agricultural supply chain management: a state of the art.European Journal of Operational Research 13619. 10.1016/j.ejor.2016.03.057 
Brusset, X. \& C. Teller, 2016. Supply Chain Capabilities, Risks, and Resilience. Intern.Journal of Production Economics. http://dx.doi.org/10.1016/j.ijpe.2016.09.008

BPTP, 2016.BukuTahunan 2016 BalaiPengkajianTeknologiPertanian (BPTP) Gorontalo. Kementrian Pertanian. Badan Penelitian dan Pengembangan Pertanian. Balai Besar Pengkajian dan Pengembangan Teknologi Pertanian.Balai Pengkajian Teknologi Pertanian. Gorontalo.

BPS, 2017. Provinsi Gorontalo dalam Angka. Badan Pusat Statistik. Gorontalo.

Chen IJ and A Paulraj. 2003. Towards a Theory of Supply Chain Management : the Constructs and Measurements. Journal of Operations Management 22 (2004) 119-150.

Christien, et al.2006. Quantifying the Agri-Food Supply Chain.Netherlands (NL): Spinger International Publisher Science.

Chopra S and P Meindl. 2004. Supply Chain Management : Strategy, Planning and Operation. Pearson Prentice Hall. United States of America.

Courtonne, et.al, 2015. Downscaling material flow analysis: The case of the cereal supply chain in France. Ecological Economics Journal 118 (2015) 67-80. http://dx.doi.org/10.1016/j.ecolecon.2015.07.007

Darma, R. 2017. Agribusiness : An Introduction to Agricultural Developemetnt. Publisher LibiliteraInstite.Makassar.

Dandageet.al , 2016. Indian perspective in food traceability: A review. Food Control Journal.10.1016/j.foodcont.2016.07.005.

Dilana, A. I. 2013.Pemasaran dan Nilai Tambah Biji Kakao di Kabupaten Madiun, Jawa Timur. Tesis. IPB. Bogor

Djuric S \& Götz, 2016. Export restrictions - Do consumers really benefit? The wheat-to-bread supply chain in Serbia. Food Policy Journal $63 \quad$ (2016) 112123..http://dx.doi.org/10.1016/j.foodpol.2016.07.002

Fajar, A.I, 2014. Analisis Rantai Pasok Jagung di Provinsi Jawa Barat. Tesis. Sekolah Pascasarjana. Instititut Pertanian Bogor.

Farid, M. dan N.A. Subekti. 2012. Tinjauan terhadap produksi,konsumsi, distribusi dan dinamika harga cabe di Indonesia. Buletin Ilmiah Litbang Perdagangan 6(2): 211-233.

Fatahilah YH, Marimin, Harianto. 2010. Analisis Kinerja Rantai Pasok Agribisnis Sapi Potong (Studi Kasus pada PT Kariyana Gita Utama, Jakarta). Jurnal Teknologi Industri Pertanian20(3):193-205.

Gang, C dan Q.Zhenhua, 2014. MaxDEA Pro 6.1. Manual. Beijing Realworld Research dan Consulting Company Ltd.

Gunasekaran, A., Patel, C. dan Mc Gaughey, R.E. 2004. A Framework for SupplyChain Performance Measurement. International Journal of Production Economics, 87 (3):pp.333347.

Govindarajan, R. 2007. Supplier Evaluation Using Data Envelopment Analysis. Working Paper 
Hartik, A. 2017.Kementan:Produksi Cabai Rawit Per Januari Masih Surplus.Rabu,11Januari 2017.http://bisniskeuangan.kompas.com. 2017/01/11.Diakses pada tanggal 11 Juli 2017.

Hayami Y, Kawagoe T, Marooka Y, dan Siregar M.1987. Agricultural Marketing and Processing in Upland Java, A Prospective From Sunda Village.Bogor (ID): The CGPRT.

Hasdiana. 2011. Disparitas Harga Cabe. Makalah disampaikan dalam Knowledge Sharing yang diselenggarakan oleh Badan Pengkajian dan Pengembangan Kebijakan Perdagangan, Jakarta, 24 Mei 2011.

Hastang, 2014. Supply Chain Sapi Potong Berbasis Peternakan Rakyat. Disertasi. Program Pascasarjana. Universitas Hasanuddin. Makassar.

$\mathrm{Hu}, \mathrm{B}$ \& Y. Feng 2017. Optimization and coordination of supply chain with revenue sharing contracts and service requirement under supply and demand uncertainty. Int. J. Production Economics 183 (2017) 185-193. http://dx.doi.org/10.1016/j.ijpe.2016.11.002

Indriani, R, R.Darma, Y.Musa, N,Tenriawaru, 2018. Economic Phenomenon of Bird's-Eye Chili Pepper (Capsicum annum) as Strategic Commodity. Research Journal of Applied Sciences. Vol.13. Issue 3.Page 189-194.Year 2018.DOI : 10.3923/rjasci.2018.189.194.

Indrajit RE dan R Djokopranoto.2002.KonsepManajemen Supply Chain Cara BaruMemandang Mata RantaiPenyediaanBarang.Grasindo. Jakarta.

Imran, S. 2008. Analisis Faktor-Faktor Produksi Usahatani Cabe rawit di Provinsi Gorontalo. Jurnal Ilmiah Agropolitan (2): 85-93.

Kurniawan, R.D, A. Suwandari, dan J.A. Ridjal, 2014. Analisis Rantai Pasokan (Supply Chain) Komoditas Cabai Merah Besar di Kabupaten Jember. Jurnal Berkala Ilmiah Pertanian. Volume 9 No.9. Bulan Maret. Hal 10-17.

Kusumaningsih, A, 2015.AnalisisIntegrasiVertikalPasarBeras di Indonesia. Buletin Bisnisdan Manajemen.Vol.01, No.02.Agustus 2015.ISSN :2442-885X.

Marimin\& N. Magfiroh, 2013.Aplikasi TeknikPengambilan Keputusandalam Manajemen Rantai Pasok. PT. Penerbit IPB Press. Bogor.

Mattevi, M \&J.Jones, 2016. Traceability in the food supply chain: Awareness and attitudes of UK Small and Medium-sized Enterprises. Food Control 64 (2016) 120e127. http://dx.doi.org/10.1016/j.foodcont.2015.12.014

Muchfirodin, Guritno, Yuliando, 2015. Supply Chain Risk Management on Tobacco Commodity in Temanggung, Central Java (Case study at Farmers and Middlemen Level). Agriculture and Agricultural Science Procedia 3 ( 2015 ) 235 - 240. The 2014 International Conference on Agro-industry (ICoA) : Competitive and sustainable Agroindustry for Human Welfare

Muslim, C dan V. Darwis, 2012.KeragaanKedelaiNasionaldanAnalisis Farmer Share sertaEfisiensiSaluranPemasaranKedelai di KabupatenCianjur.Jurnal SEPA. Vol.9 No.1 September 2012. Hal 1-11.

Nurdin, dkk. 2011. Teknologi dan Perkembangan Agribisnis Cabai di Kabupaten Boalemo Provinsi Gorontalo. Jurnal Litbang Pertanian. Volume 30 No.2. 
Ongirwalu, D.J, P.Tumade dan I.D. Palandeng, 2015. Evaluasi Hilir Rantai Pasokan dalam Sistem Logistik Komoditi Cabai di Pasar Tradisional Pinasungkulan Manado. Jurnal EMBA. Vol.3 No.1 Maret 2015. Hal 994-1001.

Padjung, R. 2016. Promoting Commodity SupplyChain in Rural Area for Job Creation. Presented at Asian Food and Agricultural Conference: Greening the Food Suply Chain, Bali 26 Octoober 2016.

Padjung, R. 2018. Improving agricultural commodity supply-chain to promote economic activities in rural area. IOP Conf. Series: Earth and Environmental Science 157 (2018) 012057 doi :10.1088/1755-1315/157/1/012057.

Pizzuti,et.al, 2017, MESCO (MEat Supply Chain Ontology): An ontology for supporting traceability in the meat supply chain. Food Control Journal (2017). http://dx.doi.org/10.1016/j.foodcont.2016.07.038

Poerwanto. 2012. Merevolusi Revolusi hijau : Manajemen Rantai Pasokan untuk Produk Pertanian. Pemikiran Guru Besar IPB. Buku III. Penerbit IPB Press. Bogor.

Potolau, M., Dumais, J.N.K, Anapu , H. Mandei, J.R., 2013. Risiko Usahatani Cabe Rawit Pada Masa Tanam I dan Masa Tanam II Di Kecamatan Ranowulu Kota Bitung. Jurnal Cocos. Vol.3 No.6.

Prasetyo, B. E, 2010. Analisis Keterpaduan Pasar Cabai Rawitantara Pasar Legi dengan Pasar Gededan Pasar Nusukan di Kota Surakarta. Skripsi. Fakultas Pertanian. Universitas Sebelas Maret. Surakarta.

Pujawan, I.N. danMahendrawathi, 2017. Supply Chain Management. Edisi 3.Penerbit Andi. Yogyakarta.

Pusdatin, 2015.Outlook KomoditasPertanianSubsektorHortikulturaCabe.Pusat Data dan Sistem Informasi Pertanian Sekretariat Jenderal Kementerian Pertanian. ISSN 1907-1507.

Rachman, F.F. 2017.Pekan Pertama 2017, Harga Cabai Rawit Merah Melambung Rp. 120.000/Kg. http://m.detik.com/finance/berita-ekonomi.Diakses pada tanggal 11 Juli 2017.

Rajagopal, 2016.Forecasting Supply Chain Performance Resilience Using Grey Prediction.Electronic Commerce Research and Applications. http://dx.doi.org/10.1016/ j.elerap. 2016.09.006.

Rahim, A dan D.R.D.Hastuti, 2007. Pengantar, Teori dan Kasus Ekonomika Pertanian. Penebar Swadaya. Jakarta.

Rahman, S. 2010. Meraup Untung Bertanam Cabai Rawit dengan Polybag. Lily Publisher Penerbit Andi. Yogyakarta.

Rahmi, E dan B. Arif, 2012. Analisis Transmisi Harga Jagung sebagai Bahan Pakan Ternak Ayam Ras di Sumatera Barat. Jurnal Peternakan Indonesia.Vol.4(2). Juni 2012.ISSN : 1907-1760.

Rusydiana, A.S. dan Tim SMART Consulting, 2013. Mengukur Tingkat Efisiensi dengan Data Envelopment Analysis (DEA) : Teori dan Aplikasi. SMART Publishing. Bogor.

Rusmadi, 2017.Pengaruh Harga Cabaiterhadap Tingkat Inflasi di Indonesia Tahun 2016.Jurnal Ilmiah Indonesia.Vol.2. No.2. Februai 2017. 
Saptana, N.K. Agustin, dan A.M. Ar-Rozi. 2012. Kinerja Produksi dan Harga Komoditas Cabai Merah. Laporan Akhir Anjak 2012.PSEKP, Bogor.

Sari, S.W, R. Nurmalina, dan B. Setiawan. Efisiensi Kinerja Rantai Pasok Ikan Lele di Indramayu, Jawa Barat. Jurnal Manajemen \& Agribisnis, Vol. 11 No. 1, Maret 2014.

SCOR (Supply Chain Operations Reference Model) Revision 11,0. 2012. Supply Chain Council. United States of America.October 2012.

Setiawan, A.Marimin, Y.Arkoma, F.Udin, 2010. Integrasi Model SCOR dan Fuzzy AHP untuk perancangan Metrik Pengukuran Kinerja Rantai Pasok Sayuran. Jurnal Manajemen dan Organisasi Vol.1 No.3.Desember 2010.

Setiawan A, Marimin, Y.Arkeman, F. Udin, 2011. Studi Peningkatan Kinerja Manajemen Rantai Pasok Sayuran Dataran Tinggi di Jawa Barat.Jurnal AGRITECH. Vol.31 No.1.Februari 2011

Sihite, S. 2017. Analisis Integrasi Pasar Kubisantara Kabupaten Karodengan Pasar Induk Medan (studikasus Kabupaten Karodengan Pasar Induk Medan).Skripsi. Program Studi Agribisnis. Fakultas Pertanian. Universitas Sumatera Utara. Medan.

Sirajuddin, S.N. 2010. Analisis Biaya Transaksi pada Usaha Sapi Perah Sistem Kemitraan dan Mandiri serta Strategi Pengembangannya di Provinsi Sulawesi Selatan. Disertasi. Sekolah Pascasarjana. Institut Pertanian Bogor. Bogor.

Singarimbun dan S.Efendi, 1983. Metode Penelitian Survai. LP3ES. Jakarta.

Soni, et.al, 2014.Measuring Supply Chain Resilience Using a Deterministic Modeling Approach.ComputersE Industrial Engineering. http://dx.doi.org/10.1016/j.cie.2014. 04.019

Suryaningrat, Amalia \& Choiron, 2015. Current Condition of Agroindustrial Supply Chain of Cassava Products: A Case Survey of East Java, Indonesia. Agriculture and Agricultural Science Procedia 3 ( 2015 ) 137 - 142. The 2014 International Conference on Agro-industry (ICoA): Competitive and sustainable Agroindustry for Human Welfare.

Sudiyono, A. 2004. Pemasaran Pertanian. Universitas Muhammadiyah Malang Press. Malang.

Subarkah, A. 2009. Kajian Kinerja Rantai Pasokan Letuce Head dengan Menggunakan DEA. Skripsi.Departemen Manajemen. Fakultas Ekonomi dan Manajemen. Institut Pertanian Bogor.

Suryanti, 2007. Membuat Aneka Olahan Cabe. Penebar Swadaya. Jakarta.

Sumarno.2011. Mengatasi Gejolak Harga Cabe dengan Menerapkan Manajemen Produksi.Tabloid Sinartani.

Syukur, M., Yunianti, R., Dermawan, R. 2017.BudidayaCabePanenSetiapHari. PenebarSwadaya. Jakarta.

Tubagus L.S, Mangantar, M., Tawas, H. 2016.Analisis Rantai Pasokan (Supply Chain) Cabai Rawit di Kelurahan Kumelembuai Kota Tomohon. Jurnal EMBA 613 Vol.4 No.2 Juni 2016, Hal. 613-621. 
Vorst, JGAJ Van der. 2006. Performance Measurement In Agri-Food Supply Chain Networks: An Overview. Wageningen : Logistics and Operations Reasearch Group Wageningen University.

Vos, J.G.M dan A.S. Duriat. Hot pepper (capsicum spp) production on Java, Indonesia : toward Integrated Crop Management. Journal Crop Protection. Volume 14 issue 3 May 1995. Pages 205-213. http:// doi.org/101016/6261-219(495)00013-c.

Wahyudi. 2011. Panen CabeSepanjangTahun. AgromediaPustaka. Jakarta.

Xing, Qian, \& Zaman, 2016. Development of a cloud-based platform for footprint assessment in green supply chain management.Journal of Cleaner Production 139 (2016).http://dx.doi.org/10.1016/j.clepro.

Yun, Y. dan A. Kurniawan, 2014. Supply Chain Logistik dalam kaitannya dengan Ketahanan Pangan di Pedesaan. Prosiding. Seminar Bisnis dan Teknologi. IBI Darmajaya. LPPPM. 15-16 Desember 2014.ISSN:2407-6171.

Yustianingsih, F. 2012. AnalisaIntegrasiPasardanTransmisiHargaBerasPetani-Konsumen di Indonesia.Tesis.Program Studi Magister PerencanaandanKebijakanPublik. Jakarta.

Zelbst, P.J. J.K.W. Green, V.E. Sower. And G.Baker. 2010. RFD Utilization and Information Sharing : the Impact on Supply Chain Performance.Journal of Bussiness and Industrial Marketing. Vol.25 (8) 582- 589. 